\title{
The effects of crowding during pregnancy on offspring emotional and sexual behavior in rats
}

\author{
ROBERT CHAPMAN, FRANK MASTERPASQUA, and RICHARD LORE \\ Douglass College, Rutgers University, New Brunswick, New Jersey 08903
}

\begin{abstract}
The effects of crowding during pregnancy on offspring behavior were examined by maintaining male and female rats in three different population densities during pregnancy. Pups were fostered to control mothers within 1 day of birth and later tested for open-field behavior, cage emergence, sexual behavior, and fertility. Although offspring of females in the most crowded group were the least likely to emerge from their cages, prenatal crowding did not influence sexual behavior or fertility, thus failing to confirm the hypothesis that prenatal crowding demasculinizes male progeny. Rats which emerged from their cages showed significantly greater open-field activity and sexual behavior than nonemergers.
\end{abstract}

Ward (1972) reported that prenatal stress induced by physical restraint of the pregnant mother under bright lights decreased male and increased female sexual behavior in male offspring rats. Similarly, Masterpasqua, Chapman, and Lore (1976) found that nonphysical maternal stress induced by the blocking of a previously learned avoidance response reduced male sexual behavior in male rat offspring. Proposing that prenatal stress disrupts the androgen-dependent process of sexual differentiation in male fetuses, Ward suggested that crowding during the prenatal period might serve as a population control mechanism. The major purpose of the present study was to determine whether crowding during pregnancy would adversely affect the reproductive potential of male and female progeny. Since a variety of prenatal stressors are known to influence offspring emotionality (see reviews by Archer \& Blackman, 1971; Joffe, 1969) we were also interested in the relationship between changes in emotional reactivity and sexual behavior.

\section{METHOD}

\section{Subjects}

Subjects included 72 offspring of Sprague-Dawley rats, 12 males and 12 females born to mothers housed during pregnancy in one of three population densities.

\section{Procedure \\ At about 150 days of age, sexually experienced Sprague-Dawley male and female rats were placed in cages measuring $66 \times 42 \times 27 \mathrm{~cm}$. In the high-density (HD) condition, eight males and eight females were placed in one cage. Although these 16 rats occupied almost the entire floor space of the cage, food and water were readily accessible. In the medium-density condition (MD), four male and four female rats shared one cage. In the low-density condition (LD), one male-female pair occupied each of 14 cages. Twenty-one days following their introduction into the cages, the}

This study was supported in part by a grant from the Rutgers Research Council to R. K. L. The assistance of Jonatham Rightmyer and Winifred Harris is gratefully acknowledged. Dr. Richard K. Lore sponsors this paper and takes full editorial, responsibility for its content. females were removed and placed singly into maternity cages to give birth. Three male and three female offspring from each of four litters per condition were fostered within 1 day of birth to mothers from the LD condition, yielding a total of 12 male and 12 female offspring per condition. Weaning occurred at 21 days of age, and each rat was housed in a standard Wahmann hanging cage for the remainder of the experiment.

Beginning at 35 days of age, each rat was placed in a square $(81 \times 81 \mathrm{~cm})$ open field divided into 64 squares for four consecutive 3-min trials. The number of squares entered as well as the number of fecal boluses were recorded. At approximately 55 days of age, each rat received a single home-cage emergence test. To initiate this test, the experimenter opened the animal's home cage 6 in. During the 5-min trial, each rat's latency to protrude any part of its body above the top of the cage and the total time spent protruding were recorded.

Each male received three weekly sexual behavior tests with an estrous female beginning at 90 days of age. Receptivity was induced in the ovariectomized lure females by a subcutaneous injection of $50-\mu \mathrm{g}$ estradiol benzoate dissolved in $3 \mathrm{cc}$ sesame oil $48 \mathrm{~h}$ before testing, and $.5 \mathrm{mg}$ progesterone dissolved in $.5 \mathrm{cc}$ sesame oil $6 \mathrm{~h}$ before testing. During each $30 \mathrm{~min}$, mounts, intromissions, and ejaculations were recorded on an event recorder. At 120 days of age, experimental males and females received a fertility test. One male and one female were placed together in a maternity cage for 1 week. The male was then removed and the female allowed to give birth. Since males and females from each of three conditions were paired in all possible combinations, nine distinct groups were formed, permitting the determination of the prenatal treatment effects on fertility for both male and female offspring.

\section{RESULTS}

Following their placement into maternal cages, all mothers whose pups served as subjects gave birth within 4 days. Data for weight change, litter size, and cannibalism, presented in Table 1, provide evidence that the intense crowding in the HD condition, but not in the MD condition, constituted an effective stressor. Despite the readily accessible supply of food and water in all conditions, HD males lost weight, while LD and MD males gained weight during the 21-day crowding period. In addition, HD females exhibited the smallest weight gain after 21 days, bore the fewest pups per litter, and showed the highest rate of cannibalism 
Table 1

Pregnancy and Litter Data for Each Group

\begin{tabular}{ccccccc}
\hline Group & $\begin{array}{c}\text { Number Male- } \\
\text { Female Pairs }\end{array}$ & $\begin{array}{c}\text { Number } \\
\text { Pregnancies }\end{array}$ & $\begin{array}{c}\text { Mean Weight } \\
\text { Change in } \\
\text { Males (grams) }\end{array}$ & $\begin{array}{c}\text { Mean Weight } \\
\text { Change in } \\
\text { Females (grams) }\end{array}$ & $\begin{array}{c}\text { Mean Litter } \\
\text { Size }\end{array}$ & $\begin{array}{c}\text { Number } \\
\text { Cannibalizing } \\
\text { Females }\end{array}$ \\
\hline LD & 14 & 14 & +19.5 & +134.9 & 14.9 & 1 \\
MD & 4 & 4 & +39.0 & +160.3 & 15.8 & 0 \\
HD & 8 & 7 & -7.0 & +101.8 & 12.5 & 3 \\
\hline
\end{tabular}

immediately following parturition. The different density conditions had little effect on fertility. All 14 LD females, all four MD females, and seven out of eight HD females bore litters.

Open-field activity was quite variable. Although the MD offspring were considerably more active (mean squares/trial $=33.2$ ) than LD offspring (mean squares/ trial $=22.3$ ) and $\mathrm{HD}$ offspring (mean squares/trial = 18.7), group differences were not significant $[F(2,66)$ $=2.36, \mathrm{p}>.05]$. A significant Treatment by Days interaction $[F(6,198)=4.09, p<.01]$ reflected an elevated mean activity on Day 1 for MD offspring. Activity decreased markedly on Day 2, producing a significant main effect for days $[F(3,198)=17.54$, $\mathrm{p}<.01)$. No sex differences approached significance for either activity or defecation. The only significant effect for defecation was the Condition by Sex by Days interaction $[F(6,198)=4.22, p<.01]$.

The results for home-cage emergence, presented in Table 2, were consistent in showing that offspring of the most densely crowded mothers were the least likely to protrude from the home cage. Significantly fewer HD offspring than $\mathrm{LD}$ and $\mathrm{MD}$ offspring emerged above the top of their home cage $\left[\chi^{2}(1)=4.5, p<.05\right]$, and HD offspring spent significantly less time protruding from their cages than offspring in less crowded conditions $[F(1,66)=11.02, p<.01]$. In addition, those HD progeny which did protrude exhibited a significantly greater latency than LD and MD emergers $[F(1,42)$ $=6.42, p<.05]$. Females spent more time protruding than males $[F(1,66)=4.37, p<.05]$ and showed shorter latencies $[F(1,42)=3.80, p<.10]$.

Cage-emergence performance also related significantly to open-field and sex behavior. Specifically, those rats that protruded at least once during the cage-emergence

Table 2

Home Cage Emergence Data for Each Group and Sex

\begin{tabular}{lcccc}
\hline \multicolumn{1}{c}{ Group } & N & $\begin{array}{c}\text { Number } \\
\text { Emerging }\end{array}$ & $\begin{array}{c}\text { Mean Time } \\
\text { Outside } \\
\text { Cage }(\mathrm{sec})\end{array}$ & $\begin{array}{c}\text { Mean Latency } \\
\text { to Emerge } \\
(\mathrm{sec})\end{array}$ \\
\hline LD Male & 12 & 8 & 7.2 & 133.3 \\
LD Female & 12 & 8 & 15.3 & 111.8 \\
MD Male & 12 & 9 & 4.5 & 148.1 \\
MD Female & 12 & 11 & 24.8 & 68.4 \\
HD Male & 12 & 6 & 3.3 & 189.2 \\
HD Female & 12 & 6 & 4.3 & 173.8 \\
\hline
\end{tabular}

Table 3

Mean Number of Mounts, Intromissions, and Ejaculations in Three Sex Tests for Each Group

\begin{tabular}{ccccc}
\hline Group & $\mathrm{N}$ & $\begin{array}{c}\text { Mean } \\
\text { Number } \\
\text { Mounts }\end{array}$ & $\begin{array}{c}\text { Mean } \\
\text { Number } \\
\text { Intromis- } \\
\text { sions }\end{array}$ & $\begin{array}{c}\text { Mean } \\
\text { Number } \\
\text { Ejacula- } \\
\text { tions }\end{array}$ \\
\hline LD & 12 & 57.4 & 31.6 & .33 \\
MD & 12 & 46.9 & 23.5 & .33 \\
HD & 9 & 55.9 & 32.2 & .67 \\
\hline
\end{tabular}

test traversed significantly more squares during the four open-field trials $(\overline{\mathrm{X}}=119.5)$ than nonemergers $(\bar{X}=58.0)$. Emerging males also mounted $(\bar{X}=66.4)$ and intromitted $(\overline{\mathrm{X}}=36.7)$ more frequently than nonemergers during sex testing $(\bar{X}=26.7$ and 12.1 , respectively). As revealed by t tests, the differences for open-field activity and mount and intromission frequencies were all significant $(p<.01)$. Emergers and nonemergers did not differ significantly for open-field defecation or fertility.

The mean number of mounts, intromissions, and ejaculations for male offspring in the three density conditions is presented in Table 3. Although the number of mounts, intromissions, and ejaculations increased over weeks for all groups, offspring males from the three conditions were indistinguishable in all three components of sexual behavior. Furthermore, there were no significant differences among conditions for either males or females on the fertility test in which $73 \%$ of pairings resulted in the birth of a litter.

\section{DISCUSSION}

In summary, the results of offspring behavioral testing showed that at least one index of emotional reactivity, home-cage emergence was affected by prenatal crowding. High-density progeny displayed a marked reluctance to emerge from their home cage as quickly or as frequently as animals in the other groups. In addition, they traversed less squares in the open-field than LD or MD offspring, although these differences were not significant. These results generally corroborate studies of mice (Keeley, 1962; Lieberman, 1963) in demonstrating that prenatal crowding can alter offspring emotional reactivity.

Yet, despite the fact that males and females in the crowded condition exhibited delterious changes in weight, litter size, and cannibalism, their progeny showed no deficiencies in sexual behavior or fertility. Hence, our results do not support Ward's (1972) hypothesis that prenatal crowding adversely affects sexual behavior in male offspring rats. 
Our results contrast with those of earlier studies in which pronounced deficits in sexual behavior did occur in the male offspring of female rats exposed to periodic stress either in the form of physical restraint (Ward. 1972) or the blocking of a previously learned avoidance response (Masterpasqua et al.. 197b). Perhaps crowding was not as severe a stressor as these treatments because the rats habituated to the crowded conditions. Alternatively. different stressors may not produce identical behavioral effects. For example. in contrast to the results of the present study, other experimenters have reported a decrease in the emotional reactivity of Sprague-Dawley offspring subsequent to prenatal handling (Ader \& Conklin. 1963), escape stress (Hutchings \& Gibbon. 197()), or avoidance response blocking (Thompson. Watson. \& Charlesworth. 1962). Furthermore, one cannot necessarily assume that overcrowding artificially produced in the laboratory will have the same behavioral effects as overpopulation in the wild.

The relationship found in this study between cage emergence and male sexual behavior deserves further study. Pottier and Baran (1973) reported that male rats which persistently fail to mate show a general behavioral syndrome characterized by inactivity and a refractoriness in responding to novel stimuli. Their description of noncopulators is consistent with the relative lack of cage emergence of noncopulators in this study. Differences between emergers and nonemergers were not found to be present in the fertility test. suggesting that the inhibition of sexual behavior in highly emotional rats was overridden by prolonged exposure to the female.

\section{REFERENCES}

Ader, R., \& ConkıIN, P. M. Handling of pregnant rats:
Effects on emotionality of their offspring. Science, 1963, 142. 411-412.

ArCher, J. E., \& Blackman, D. E. Prenatal psychological stress and offspring behavior in rats and mice. Developmental Psychobiology, 1971, 4, 193-248.

Hutchings, D. E., \& Gibbon, J. Preliminary study of behavioral and teratogenic effects of two "stress" procedures administered during two different periods of gestation in the rat. Psychological Reports, 1970, 26, 239-246.

JofFE, J. M. Prenatal determinants of behavior. Oxford: Pergamon Press, 1969.

KEELEY, $K$. Prenatal influences on behavior of offspring of crowded mice. Science, 1962, 135, 44-45.

LIEBERMAN, M. W. Early development stress and later behavior. Science, 1963, 141, 824-825.

Masterpasqua, F., Chapman, R., \& Lore, R. The effects of prenatal psychological stress on the sexual behavior and reactivity of male rats. Developmental Psychobiology, 1976, 9, in press.

Pottier, J. J. G., \& BARAN, D. A general behavioral syndrome associated with persistent failure to mate in the male laboratory rat. Journal of Comparative and Physiological Psychology, 1973, 83, 499-509.

Thompson, W. R., Watson, J., \& Charlesworth. W. R. The effects of prenatal maternal stress on offspring behavior in rats. Psychological Monographs, 1962, 76 (Whole No. 38).

WARD, I. L. Prenatal stress feminizes and demasculinizes the behavior of males. Science, 1972, 175, 82-84.

(Received for publication February 9, 1976.) 